\title{
3 Research Square

\section{Effect of Continuous Hypertonic Saline Infusion on Clinical Outcomes in Patients with Traumatic Brain Injury: A Retrospective Causal Analysis}

\section{Chi Peng}

Naval Medical University

\section{Fan Yang}

Fourth Military Medical University: Air Force Medical University

Chenxu Zhang

Naval Medical University

Lulong Bo

Naval Medical University

Jian Yu

Naval Medical University

\section{Liwei Peng}

Fourth Military Medical University: Air Force Medical University

\section{Weixin Li}

Fourth Military Medical University: Air Force Medical University

Zhichao Jin ( $\nabla$ jinzhichao@smmu.edu.cn )

Naval Medical University

\section{Research}

Keywords: Traumatic brain injury, Hypertonic saline, Clinical outcome, Marginal Structure Cox Model, Causal analysis

Posted Date: August 23rd, 2021

DOI: https://doi.org/10.21203/rs.3.rs-805195/v1

License: (c) (1) This work is licensed under a Creative Commons Attribution 4.0 International License. Read Full License 


\section{Abstract}

Purpose: Intracranial pressure (ICP) control has long been recognized as an important requirement for traumatic brain injury (TBI) patients. Nevertheless, the long-term effect of hypertonic saline (HTS) remains unknown. The aim of this study was to elucidate the effect on clinical outcomes in TBI patients admitted to intensive care unit (ICU) settings.

Methods: We retrospectively identified moderate to severe TBI patients from two public databases named Medical Information Mart for the Intensive Care (MIMIC)-IV and eICU Collaborative Research Database (elCU-CRD). A marginal structural Cox model (MSCM) was used, with time-dependent variates designed to reflect exposure over time during the ICU stay. A trajectory modeling, based on intracranial pressure evolution pattern, allowed identification of subgroups.

Results: Overall, in our cohort of 1955 eligible patients, 130 (6.65\%) received HTS. MSCM indicated that the HTS was significantly associated with better Glasgow coma score [(GCS): hazard ratio (HR) 1.19, $95 \%$ confidence interval $(95 \% \mathrm{Cl}) 1.01-1.40, p=0.041$ ], higher infection complications [eg. urinary tract infection (HR 1.88, 95\% Cl 1.26-2.81, p = 0.002)], and increased ICU LOS (HR 2.02, 95\% Cl 1.71-2.40, $\mathrm{p}<$ 0.001 ). A protective effect from GCS by the HTS was found in the subgroup with medium and low ICP.

Conclusion: Our study revealed no significant difference in the all-cause mortality rates between patients receiving HTS or not. Increased occurrence rates of infection and electrolyte imbalance were inevitable outcomes caused by continuous HTS infusion. Although the study suggested the slight beneficial effects including better neurological outcome, the results warrant further validation.

\section{Introduction}

Traumatic brain injury (TBI), a severe condition observed in trauma patients, is estimated to jeopardize 69 million individuals in 2019 worldwide, possessing a high mortality rate[1]. And it is reported that nearly $33 \%$ of patients with TBI die in hospital[2]. Thanks to prompt surgical and medical management, the mortality has steadily reduced in the past few decades, however, the incomplete recovery still contributes to TBI survivors with varying degrees of neurological disability, specifically, adverse sequelae and changes in quality of life[3-5].

Intracranial pressure (ICP) represents a major predictor of neurological deterioration in patients with TBI, with elevated ICP being associated with poor neurological outcome[6]. Hypertonic saline (HTS) is regarded as the mainstay for treatment of elevated ICP in TBI. HTS agent might exert an early effect on ICP by decreasing blood viscosity and hematocrit, improving cerebral blood flow (CBF), and oxygen delivery, which in turn reduce cerebral blood volume (CBV) and ICP[7]. Thus, there may be a role for HTS administration to avoid progressive cerebral edema, subsequent neurological deterioration and secondary cognitive disorder. 
However, there are concerns that HTS use may trigger acute kidney injury (AKI), hypernatremia and hyperchloremia, which, further, were independently associated with in-hospital mortality in patients with moderate-severe TBI (msTBI)[8, 9]. And the fourth edition of the Brain Trauma Foundation's Guidelines states that there is insufficient evidence to support the application of any specific hyperosmolar drug for patients with msTBI[10]. Other guidelines do not elucidate the direct effect on clinical outcome associated with the use of HTS or just are based on low-quality evidence[11, 12]. Furthermore, the predominance of literature focused on severe TBI, whereas milder forms of TBI remain unclear.

In particular, the role of HTS administration in patients with msTBI, defined as Glasgow Coma Score $(G C S)<12$ remains uncertain, with physiologic studies showing benefit and clinical studies suggesting harm $[13,14]$. Although one retrospective study incorporated HTS as the time-dependent variable by conventional Cox analysis, its credibility was limited by residual confounding, inappropriate accounting for dynamic interaction between time-varying treatment and confounders[15].

It is noted that these publications were limited by the single hospital sampling, limited variables, insufficient statistic power, and a lack of effective control for time-varying confounders. In fact, the treatment with HTS, a long-term dynamic variable that changes over time, depends on sodium and chloride. However, there are concerns that performing a randomized controlled trial (RCT) may not be ethical, thus, we emulated an analysis of a hypothetical trial through the use of observational longitudinal data to achieve causal inference. Thus, this present article aimed to investigate the causal effect of HTS on the clinical outcomes in TBI patients from two large intensive care unit (ICU) databases. Additionally, with an aim to explore the heterogeneity of the data, a trajectory modeling based on longitudinal/dynamic ICP evolution pattern during ICU stay was achieved.

\section{Methods}

\section{Data source and ethics approval}

A longitudinal, multi-center, retrospective study of TBI patients from two sizeable critical care databases, the Medical Information Mart for Intensive Care (MIMIC)-IV version 1.0[16] and eICU Collaborative Research Database (eICU-CRD) version 1.2[17] was conducted. In brief, the MIMIC-IV database, an updated version of MIMIC-III, incorporated comprehensive, de-identified data of patients admitted to the ICUs at the Beth Israel Deaconess Medical Center in Boston, Massachusetts, between 2008 and 2019, containing data from 383220 distinct admissions (single center). The other database, elCU-CRD, was a multicenter, freely available, sizeable database with de-identified high granularity health data associated for over 200,000 admissions to ICUs across the United States between 2014 and 2015. One author (CP) has obtained access to both databases and was responsible for data extraction (Certification number: 41657645). Since the study was an analysis of the anonymized publicly available databases with preexisting institutional review board (IRB) approval from the Massachusetts Institute of Technology (MIT) and Beth Israel Deaconess Medical Center (BIDMC), informed consent was also waived. The study was 
reported accordance to the REporting of studies Conducted using Observational Routinely collected health Data (RECORD) statement[18].

\section{Participant selection}

Inclusion criteria were patients with msTBI. People with an age of less than 16 years old, ICU stays less than $48 \mathrm{~h}$, osmotherapy use prior to ICU admission, cervical spinal cord injury, and bolus injection were excluded from the study. Moreover, for patients with ICU admissions more than once, only data of the first ICU admission of the first hospitalization were included in the analysis.

\section{Data collection}

In this study, the data were extracted from MIMIC-IV and eICU-CRD including age, gender, race, weight, body mass index (BMI), admission type, smoking history. Coexisting disorders were also collected based on the recorded International Classification of Diseases (ICD)-9 and ICD-10 codes. Then, the Charlson comorbidity index $(\mathrm{CCl})$ was calculated from its component variables. Lastly, we extracted data containing laboratory parameters, injury details, multiple scoring systems, medication use, ICU interventions, and neurosurgical interventions on the first day of ICU admission. Laboratory variables of HTS, sodium and chloride were measured during the entire ICU stay. For patients with multiple measurements, the minimum daily value of serum sodium and chloride was included in the analysis owing to the fact that it was related to the greatest severity of illness.

\section{Primary and secondary outcomes}

The primary outcomes were all-cause mortality, GCS value on the day of discharge. Secondary outcomes incorporated AKI, infection complications [Urinary tract infection (UTI), pneumonia, sepsis], electrolyte imbalance (defined as hyperchloremia, hypernatremia), ICU length of stay (LOS) and hospital LOS. Then, a trajectory modelling based on ICP evolution pattern during ICU stay was established.

\section{Statistical analysis}

Values were presented as the means with standard deviations (if normal) or medians with interquartile ranges (IQR) (if non-normal) for continuous variables, and total numbers with percentages for categorical variables. Proportions were compared using $\chi^{2}$ test or Fisher exact tests while continuous variables were compared using the t test or Wilcoxon rank sum test, as appropriate.

\section{Marginal structure Cox model (MSCM)}

In this study, HTS, a time-dependent variable, was dichotomized as "any dose of HTS exposure versus none" on a daily basis. The daily use of HTS was predicted by both time-fixed covariates and timevarying confounders including sodium and chloride to facilitate casual interference. In the first step, the probability of receiving HTS at each follow-up day was estimated by both time-fixed and time-varying covariates, and then inverse probability of treatment weighting (IPTW) was calculated. In the second step, covariates were balanced across the population to attempt to emulate RCT at the time of the HTS 
exposure period[19]. Then, a causal estimate of the treatment's effect on the study outcome was estimated. Details of MSCM can be seen at electronic supplemental material (ESM).

\section{Grouped based trajectory modeling}

Group-based trajectory modeling (GBTM) is an established analytical technique used to identify hourly ICP clusters following a similar progression of changes over time on a given variable[20]. Details on GBTM are also reported in the ESM.

\section{Sensitivity Analysis}

To increase the robustness of our findings, pre specified subgroup analyses stratified by age, gender, BMI, ICP, blood sodium level, blood chloride level, severity of injury, CCl and injury severity score (ISS) were performed. Moreover, the patterns assumed missing to be completely at random, so multiple imputation approach was used to iterate the original data (ESM table S1)[21]. Ultimately, unmeasured confounding may bias the estimates from this observation study, thus, the E-value was also computed to further evaluate the robustness of the findings[22, 23]. The E-value indicated how strongly an unmeasured confounder would have to be associated with both the HTS use and the outcomes of interest to reduce the observed effect to the null, conditional on the measured covariates.

Statistical significance was considered to be at two-sided $p<0.05$. All analyses were performed with $R$ version 4.0.2 (http://www.R-project.org) and STATA (version 16.0; Stata Corporation, College Station, TX, USA).

\section{Results}

\section{Study cohort}

Initially, the search identified 382278 adult ICU admissions from the MIMIC- IV database and 200859 ones from the eICU-CRD database, respectively. Of these, 10542 were diagnosed with TBI. According to the exclusion criteria, 1955 patients were finally included in the study cohort. Of this cohort, 130 patients were treated with HTS, while the remaining patients not (Fig. 1). The baseline characteristics of the HTS and non-HTS groups are described in Table 1 and ESM table S2. Patients in the HTS group were likely to be younger [55.00 (IQR 29.00-69.00) vs. 63.00 (IQR 44.00-79.00) years, $p<0.001$ ], Asian (3.85\% vs. $1.70 \%, p<0.001)$, have smoking history ( $30.77 \%$ vs. $20.71 \%, p=0.010)$, lower CCI [2.00 (IQR 0.00-4.75) vs. 4.00 (IQR1.00-5.00); $p=0.019$ ] than the non-HTS group. On the first day of ICU admission, HTS group showed lower sodium [137.25 (IQR 133.07-141.23) vs. 139.00 (IQR 136.67-141.70) $\mathrm{mmol} / \mathrm{L} ; \mathrm{p}=0.005]$, lower creatinine [70.72 (IQR 61.88-88.40) vs.79.56 (IQR 61.88-97.24) mmol/L; $p=0.018]$, lower BUN [13.00 (IQR 10.00-17.00) vs. 15.00 (IQR 11.00-21.30) mg/dL, $\mathrm{p}<0.001]$, more severe TBI (70.77\% vs. $61.15 \%, p=0.037)$, less subarachnoid hemorrhage and cranial extradural hematoma [( $11.54 \%$ vs. $24.33 \%$, $p=0.001),(0.00 \%$ vs. $2.90 \%, p=0.046)]$, more cerebral contusion $(15.38 \%$ vs. $8.99 \%, p=0.024)$, more unintentional falls, motor vehicle crashes, and firearm injuries [( $48.46 \%$ vs. $27.84 \%, p<0.001),(40.77 \%$ vs. $26.36 \%, p=0.001),(2.31 \%$ vs. $0.22 \%, p=0.008)]$ than the non-HTS group. In general, patients in the HTS 
group were less critically ill than the non-HTS group [sepsis related organ failure assessment (SOFA): 5.00 (IQR 4.00-7.00) vs. 6.00 (IQR 4.00-8.00); $p=0.037$ ]. With regard to treatment, patients treated with HTS were more likely to receive barbiturates $(3.08 \%$ vs. $0.33 \%, p=0.003)$, hypothermia $(1.54 \%$ vs. $0.11 \%$, $p=0.024)$, craniectomy $(10.00 \%$ vs. $1.59 \%, p<0.001)$, simultaneously, with lower ICP [9.00 (IQR 9.00, $17.00)$ vs. 29.00 (IQR 19.00-40.00), p<0.001]. 
Table 1

Baseline characteristic of the included TBI patients stratified by continuous HTS use

\begin{tabular}{|c|c|c|c|c|}
\hline Variables & ALL $(n=1955)$ & HTS $(n=130)$ & $\begin{array}{l}\text { Non-HTS }(n= \\
1825)\end{array}$ & $\begin{array}{l}P \\
\text { Value }\end{array}$ \\
\hline \multicolumn{5}{|l|}{ Demographics } \\
\hline Median age (IQR), y & $\begin{array}{l}62.00(43.00 \\
79.00)\end{array}$ & $\begin{array}{l}55.00(29.00 \\
69.00)\end{array}$ & $\begin{array}{l}63.00(44.00 \\
79.00)\end{array}$ & $<0.001$ \\
\hline Male, n (\%) & $1294(66.22)$ & 92 (70.77) & $1202(65.90)$ & 0.299 \\
\hline Race, n (\%) & & & & $<.001$ \\
\hline Black & $138(7.06)$ & $6(4.62)$ & $132(7.23)$ & \\
\hline White & 1341 (68.59) & $63(48.46)$ & 1278 (70.03) & \\
\hline Hispanic & $70(3.58)$ & $4(3.08)$ & $66(3.62)$ & \\
\hline Asian & $36(1.84)$ & $5(3.85)$ & $31(1.70)$ & \\
\hline Others & $370(18.93)$ & $52(40.00)$ & $318(17.42)$ & \\
\hline Weight, kg & $\begin{array}{l}76.45(64.60 \\
90.00)\end{array}$ & $\begin{array}{l}75.35(64.75 \\
90.98)\end{array}$ & $\begin{array}{l}76.60(64.60 \\
90.00)\end{array}$ & 0.990 \\
\hline BMI (IQR), kg/m² & $\begin{array}{l}25.90(22.80 \\
30.00)\end{array}$ & $\begin{array}{l}25.30(22.50 \\
30.70)\end{array}$ & $\begin{array}{l}25.90(22.90 \\
29.90)\end{array}$ & 0.866 \\
\hline Smoking history & $418(21.38)$ & $40(30.77)$ & $378(20.71)$ & 0.010 \\
\hline CCl, median (IQR) & $3.00(1.00,5.00)$ & $2.00(0.00,4.75)$ & $4.00(1.00,5.00)$ & 0.019 \\
\hline \multicolumn{5}{|l|}{ Electrolyte } \\
\hline Sodium, $\mathrm{mmol} / \mathrm{L}$ & $\begin{array}{l}139.00(136.50 \\
141.70)\end{array}$ & $\begin{array}{l}137.25(133.07 \\
141.23)\end{array}$ & $\begin{array}{l}139.00(136.67 \\
141.70)\end{array}$ & 0.005 \\
\hline Chloride, $\mathrm{mmol} / \mathrm{L}$ & $\begin{array}{l}106.00(102.00 \\
110.00)\end{array}$ & $\begin{array}{l}104.50(100.75 \\
109.00)\end{array}$ & $\begin{array}{l}106.00(102.00 \\
110.00)\end{array}$ & 0.158 \\
\hline Potassium, mmol/L & $3.90(3.60,4.20)$ & $3.80(3.60,4.10)$ & $3.90(3.60,4.20)$ & 0.600 \\
\hline $\begin{array}{l}\text { Plasma osmolality, } \\
\mathrm{Osm} / \mathrm{kg} . \mathrm{H}_{2} \mathrm{O}\end{array}$ & $\begin{array}{l}302.00(292.00 \\
312.00)\end{array}$ & $\begin{array}{l}304.50(295.00 \\
314.00)\end{array}$ & $\begin{array}{l}300.50(291.00 \\
312.00)\end{array}$ & 0.191 \\
\hline
\end{tabular}

TBI traumatic brain injury, HTS hypertonic saline, IQR interquartile range, BMI body mass index, AIDS Acquired Immune Deficiency Syndrome

$\mathrm{CCl}$ Charlson comorbidity index, BUN blood urea nitrogen, GCS glascow coma score, SOFA sepsis related organ failure assessment, APSIII acute physiology score III, ISS injury severity score, ICU intensive care unit, ICP intracranial pressure 


\begin{tabular}{|c|c|c|c|c|}
\hline Variables & ALL $(n=1955)$ & HTS $(n=130)$ & $\begin{array}{l}\text { Non-HTS }(n= \\
1825)\end{array}$ & $\begin{array}{l}P \\
\text { Value }\end{array}$ \\
\hline Creatinine, $\mu \mathrm{mol} / \mathrm{L}$ & $\begin{array}{l}79.56(61.88 \\
97.24)\end{array}$ & $\begin{array}{l}70.72(61.88 \\
88.40)\end{array}$ & $\begin{array}{l}79.56(61.88 \\
97.24)\end{array}$ & 0.018 \\
\hline BUN, mg/dL & $\begin{array}{l}15.00(11.00 \\
21.00)\end{array}$ & $\begin{array}{l}13.00 \\
(10.00,17.00)\end{array}$ & $\begin{array}{l}15.00(11.00 \\
21.30)\end{array}$ & $<0.001$ \\
\hline $\begin{array}{l}\text { Renal replacement } \\
\text { therapy, } \mathrm{n}(\%)\end{array}$ & $49(2.51)$ & $2(1.54)$ & $47(2.58)$ & 0.769 \\
\hline TBI severity & & & & 0.037 \\
\hline $\begin{array}{l}\text { Moderate TBI (GCS 9- } \\
\text { 12) }\end{array}$ & $747(38.21)$ & $38(29.23)$ & 709 (38.85) & \\
\hline Severe TBI $(\mathrm{GCS}<=8)$ & $1208(61.79)$ & $92(70.77)$ & $1116(61.15)$ & \\
\hline \multicolumn{5}{|l|}{ Type of injury, $n$ (\%) } \\
\hline $\begin{array}{l}\text { Subarachnoid } \\
\text { hemorrhage }\end{array}$ & $459(23.48)$ & $15(11.54)$ & $444(24.33)$ & 0.001 \\
\hline $\begin{array}{l}\text { Cranial extradural } \\
\text { hematoma }\end{array}$ & $53(2.71)$ & $0(0.00)$ & $53(2.90)$ & 0.046 \\
\hline Cerebral contusion & $184(9.41)$ & $20(15.38)$ & 164 (8.99) & 0.024 \\
\hline \multicolumn{5}{|l|}{$\begin{array}{l}\text { Mechanism of injury, } n \\
\text { (\%) }\end{array}$} \\
\hline Unintentional falls & $571(29.21)$ & $63(48.46)$ & $508(27.84)$ & $<0.001$ \\
\hline Motor vehicle crashes & $534(27.31)$ & $53(40.77)$ & $481(26.36)$ & 0.001 \\
\hline Firearm injuries & $7(0.36)$ & $3(2.31)$ & $4(0.22)$ & 0.008 \\
\hline \multicolumn{5}{|l|}{ Scoring systems } \\
\hline SOFA & $6.00(4.00,8.00)$ & $5.00(4.00,7.00)$ & $6.00(4.00,8.00)$ & 0.037 \\
\hline APSIII & $\begin{array}{l}55.00(40.00 \\
74.00)\end{array}$ & $\begin{array}{l}55.00(41.75 \\
74.00)\end{array}$ & $\begin{array}{l}55.00(40.00 \\
74.00)\end{array}$ & 0.647 \\
\hline ISS & & & & 0.282 \\
\hline$>=15$ & 1199 (61.33) & $86(66.15)$ & $1113(60.99)$ & \\
\hline$<15$ & $756(38.67)$ & $44(33.85)$ & $712(39.01)$ & \\
\hline \multicolumn{5}{|c|}{$\begin{array}{l}\text { TBI traumatic brain injury, HTS hypertonic saline, IQR interquartile range, BMI body mass index, AIDS } \\
\text { Acquired Immune Deficiency Syndrome }\end{array}$} \\
\hline $\begin{array}{l}\mathrm{CCI} \text { Charlson comorbic } \\
\text { related organ failure a } \\
\text { intensive care unit, ICP }\end{array}$ & $\begin{array}{l}\text { ex, BUN blood ure } \\
\text { ent, APSIII acute } \\
\text { anial pressure }\end{array}$ & $\begin{array}{l}\text { rogen, GCS glasc } \\
\text { iology score III, IS }\end{array}$ & $\begin{array}{l}\text { oma score, SOFA } \\
\text { ury severity score, }\end{array}$ & \\
\hline
\end{tabular}




\begin{tabular}{|c|c|c|c|c|}
\hline Variables & ALL $(n=1955)$ & HTS $(n=130)$ & $\begin{array}{l}\text { Non-HTS }(n= \\
1825)\end{array}$ & $\begin{array}{l}P \\
\text { Value }\end{array}$ \\
\hline \multicolumn{5}{|l|}{ Medication use } \\
\hline Vasopressin & $104(5.32)$ & $9(6.92)$ & $95(5.21)$ & 0.522 \\
\hline Barbiturates & $10(0.51)$ & $4(3.08)$ & $6(0.33)$ & 0.003 \\
\hline \multicolumn{5}{|l|}{ ICU interventions } \\
\hline Maximum ICP, mmHg & $9.00(9.00,25.00)$ & $9.00(9.00,17.00)$ & $\begin{array}{l}29.00(19.00 \\
40.00)\end{array}$ & $<.001$ \\
\hline Hypothermia & $4(0.20)$ & $2(1.54)$ & $2(0.11)$ & 0.024 \\
\hline Hyperventilation & $1831(93.66)$ & $121(93.08)$ & 1710 (93.70) & 0.924 \\
\hline \multicolumn{5}{|l|}{$\begin{array}{l}\text { Neurosurgical } \\
\text { interventions }\end{array}$} \\
\hline Craniectomy & $42(2.15)$ & $13(10.00)$ & 29 (1.59) & $<.001$ \\
\hline Ventriculostomy & $66(3.38)$ & $2(1.54)$ & $64(3.51)$ & 0.316 \\
\hline \multicolumn{5}{|c|}{$\begin{array}{l}\text { TBI traumatic brain injury, HTS hypertonic saline, IQR interquartile range, BMI body mass index, AIDS } \\
\text { Acquired Immune Deficiency Syndrome }\end{array}$} \\
\hline \multicolumn{5}{|c|}{$\begin{array}{l}\mathrm{CCI} \text { Charlson comorbidity index, BUN blood urea nitrogen, GCS glascow coma score, SOFA sepsis } \\
\text { related organ failure assessment, APSIII acute physiology score III, ISS injury severity score, ICU } \\
\text { intensive care unit, ICP intracranial pressure }\end{array}$} \\
\hline
\end{tabular}

\section{Marginal structural cox model}

As expected, the first step in fitting MSCM indicated that sodium (HR for each $3 \mathrm{mmol} / \mathrm{L}$ decrease 0.80 ; 95\% $\mathrm{Cl} 0.75-0.95 ; \mathrm{p}=0.017$ ), chloride (HR for each $1 \mathrm{mmol} / \mathrm{L}$ decrease $0.94 ; 95 \% \mathrm{Cl} 0.91-0.97 ; p<0.001$ ) were important predictors of continuous HTS infusion (ESM table S3). Other independent predictors included age, unintentional falls, motor vehicle crashes, GCS and ISS. Weights distribution plot for the IPTW is shown in Fig. 2. By adjusting for both baseline and time-varying covariates, the association between HTS and clinical outcomes was investigated in the MSCM. Interestingly, it has to be noted that continuous HTS infusion was associated with better neurological outcomes (GCS: HR 1.19; 95\% $\mathrm{Cl} 1.01-$ $1.40 ; p=0.041$ ). Similarly, with respect to secondary outcomes, the study identified significant effect of HTS on urinary tract infection (HR 1.88; 95\% Cl 1.26-2.81; $\mathrm{p}=0.002$ ), sepsis (HR 2.66; 95\% Cl 2.21-3.22; $\mathrm{p}<0.001$ ), hyperchloremia ( $\mathrm{HR} 4.53 ; 95 \% \mathrm{Cl} 3.78-5.44 ; \mathrm{p}<0.001$ ), hypernatremia ( $\mathrm{HR} \mathrm{3.66;95 \%} \mathrm{Cl} 2.50-$ 5.38; $p$ <.001). Also, MSCM results showed that HTS was associated with significantly increased ICU LOS (HR 2.02; 95\% Cl 1.71-2.40; $p<0.001$ ), hospital LOS (HR 1.77; 95\% Cl 1.44-2.20; $<<0.001$ ) in the overall msTBI patients (Table 2). In the entire cohort, continuous infusion of HTS was not associated with 30-day mortality (HR 0.93; $95 \% \mathrm{Cl} \mathrm{0.64-1.79;} \mathrm{p}=0.786)$, nonetheless, the subgroup sensitivity analysis 
indicated that the increased mortality was found in the obesity group (BMI: $>=30 \mathrm{vs}<30 \mathrm{~kg} / \mathrm{m}^{2}, \mathrm{HR} 1.13$, $95 \% \mathrm{Cl} 0.87-1.47$, p for interaction $=0.019)($ ESM Fig. 1$)$.

Table 2

Impact of HTS on clinical outcomes by a marginal structural cox model

\begin{tabular}{lllll} 
Outcomes & Model 1 & \multicolumn{1}{c}{ Model 2 } & \\
& HR $(95 \% \mathrm{Cl})$ & $P$ Value & HR $(95 \% \mathrm{Cl})$ & $P$ Value
\end{tabular}

\section{Primary outcomes}

\begin{tabular}{lllll} 
All-cause mortality (30 days) & $0.83(0.48,1.36)$ & 0.477 & $0.93(0.64,1.79)$ & 0.786 \\
\hline GCS value on the day of discharge & $2.08(1.16,4.16)$ & 0.012 & $1.19(1.01,1.40)$ & 0.041
\end{tabular}

Secondary outcomes
AKI
$0.70(0.36,1.24)$
0.232
$0.64(0.34,1.19)$
0.159

Infection complications

Urinary tract infection

$1.93(1.24,2.94) \quad 0.004 \quad 1.88(1.26,2.81) \quad 0.002$

Pneumonia

$1.08(0.57,1.89)$

0.805

$1.25(0.66,2.38)$

0.488

Sepsis

$5.08(3.38,7.86)<0.001$

$2.66(2.21,3.22) \quad<0.001$

Electrolyte imbalance

Hyperchloremia

$8.06(5.41,12.3) \quad<0.001$

$4.53(3.78,5.44) \quad<0.001$

Hypernatremia

$3.81(2.48,5.73)<0.001$

$3.66(2.50,5.38)$

$<0.001$

ICU LOS, days, median (IQR) (6)

$4.11(2.63,6.74)<0.001$

$2.02(1.71,2.40)$

$<0.001$

Hospital LOS, days, median (IQR) (13)

$2.70(1.83,4.06)$

$<0.001$

$1.77(1.44,2.20)$

$<0.001$

Model 1 (unadjusted model): unadjusted, Model 2 (Marginal structural model): adjusted for baseline and time-varying covariables

HTS hypertonic saline, HR hazard ratio, Cl confidence interval, ICU intensive care unit, LOS length of stay, IQR interquartile range

AKI acute kidney injury, DVT deep venous thrombosis, GCS glascow coma scale, ICP intracranial pressure, MV mechanical ventilation

E values for the observed estimates of association between HTS and in-hospital outcomes are shown in the ESM Table S4, for instance, the E-value for GCS value was 1.66, with a lower confidence limit of 1.11, showing that unmeasured confounders were unlikely to explain the entirety of the treatment effect.

\section{Trajectory modeling analysis}

According to the trajectory modeling, five subgroups of patients with distinct ICP evolution pattern during their ICU stay were identified (Fig. 3). The ICP patterns of the different subgroups can be seen as follows: 
Group 1: persistently high ICP subgroup: 83 (IQR, 40-90), Group 2: low ICP subgroup: 8 (IQR, 5-13), Group 3: medium ICP subgroup: 15 (IQR, 12-18), Group 4: high ICP subgroup: 23 (IQR, 19-29), Group 5: relatively high ICP subgroup: 32 (IQR, 21-48). Detailed information of HTS infusion and main outcomes among subgroups are shown in the ESM table S5.

With regard to the percentage of HTS infusion, the difference between the five subgroups was not statistically significant. In contrast, there were fewer death events and better neurological outcomes in the subgroup with the low and medium ICP level. Owing to the fact that $92 \%$ patients were in the group 2 and 3 , thus, the further subgroup analyses were conducted in these two subgroups. Continuous infusion of HTS was not associated with a lower risk of death for the medium and low ICP subgroup [(HR 0.54; $95 \%$ Cl 0.08-2.13; $p=0.525)$, (HR 1.67; 95\% Cl 0.47-5.30; $p=0.411)]$. However, HTS infusion was associated with increased GCS in these two groups [(HR 4.02; 95\% Cl 1.02-29.1; $p=0.046),(\mathrm{HR} 4.77 ; 95 \% \mathrm{Cl} 1.19-$ 35.0; $p=0.025)$ ] (ESM table S6).

\section{Discussion}

To the best of our knowledge, this is the first, multicenter, longitudinal study indicating the effect of continuous HTS infusion on in-hospital outcome among msTBI patients while addressing simultaneously the time-varying nature of this type of exposure. We found that the utility of HTS was not independently associated with mortality, but with better neurological outcomes, increased infection complications, DVT, hyperchloremia, hypernatremia, LOS, and sedation duration. By characterizing the ICP trajectories of patients, we also identified that HTS was associated with better neurological outcome in the medium and low ICP subgroups.

Of note, cerebral edema develops from several pathologic mechanisms following TBI, leading to cerebral herniation and a rapid worsening of prognosis[24, 25]. Nevertheless, the availability of neurosurgical interventions in most medical facilities is limited, means of inducing a hyperosmolar environment including HTS are currently proposed[26]. Accordingly, the effects of HTS on TBI patients need to be further explored.

As expected, in this passage, both hypernatremia and hyperchloremia are both causes and results of HTS. Similarly, previous studies have also concluded that if not properly controlled, continuous infusion of HTS may bring hypernatremia and hyperchloremia, accompanied by the increased in-hospital mortality[27, 28].

Moreover, in this study, continuous HTS infusion did significantly improve neurological outcome as assessed by the GCS value on the day of discharge. Relatively more severe TBI (moderate: 747 vs severe: 1208) patients have increased the power to indicate the impact of HTS owing to the fact that the risk of intracranial hypertension or brain edema is higher in this population[29]. The precise regulatory mechanism remains to be further elucidated. Perhaps, the efficacy of HS in brain edema resulting from TBI was closely associated with the downregulation of aquaporin-4 (AQP4), the restoration of brain blood 
barrier (BBB) integrity and the suppression of inflammatory factors including Interleukin (IL-1 $\beta$ ), tumor necrosis factor (TNF-a), NF-kB[30].

Furthermore, our study provided evidence that continuous HTS infusion was not significantly associated with mortality. It is worth noting that our passage was able to elucidate that the mortality described was related to an underlying medical condition itself, not other confounders, including hypernatremia or hyperchloremia. Congruently, a 2021COBI RCT published in JAMA found that there was no significant difference in 6-month mortality between the HTS group and control group[31]. Likewise, Tan SK et al[15] found that HTS was not associated with hospital mortality in patients with severe TBI. Yet one systematic review concluded that HTS was associated with a reduction of in-ICU mortality[32]. Given the heterogeneity of the included population, we planned a subgroup analysis to account for this possibility. Specifically, restricting the analysis to the subgroup of obesity patients did demonstrate a higher mortality. In this regard, studies conducted by Brown CV et al, Chabok SY et al had similar results to ours[33,34]. Further, this adverse effect seems to be due to age, lower admission blood pressure, and more associated chest injury, rather than a direct result of the obese state, however, this speculation needs further validation[33].

In addition, our findings added additional evidence to previous studies suggesting that continuous HTS infusion did not result in increased AKI, suggesting no harm to the kidney[35,36]. An important factor may be that, in ICU, patients were kept in euvolemia or mild hypervolemia, despite supraphysiologic serum sodium and serum osmolarity.

Nevertheless, a concerning finding was the association between continuous HTS infusion and increased infection and LOS. Previous clinical trials concerning continuous HTS infusion and infection were limited with mixed results; some reported increased infection[35] while others did not[37, 38]. Physiologically, high sodium levels have demonstrated suppressive effects on leukocyte activation and could theoretically impair the immune system, resulting in higher infection rates[39]. As hypothesized, previous studies have suggested that increased LOS may be due to multiple complications, especially, hypernatremia and infection. Further studies might be needed to confirm the above assumptions.

To further explore the association of HTS on in-hospital outcomes and provide an insight into the mechanisms by which ICP level produces this effect, we characterized the ICP trajectories and estimated the impact of ICP burden on outcomes. Indeed, the heterogeneity of the included population in terms of ICP evolution pattern was evidenced. Although case mixes were different from one subgroup to the others, a protective effect was found in the low and medium ICP subgroups, which was consistent with the result of MSCM, adding the robustness to our findings.

The strength of our study lied in a population-based longitudinal cohort from multi-center in US, a highquality data with granular temporal detail, a homogeneous population, accordingly, ensuring the robustness, reliability, generalizability of the findings. Apart from this, to estimate the causal effect of HTS administration on in-hospital outcome, we employed MSCM, which helped align results from an observational study with those of actual randomized controlled trials. Moreover, by implementing 
multiple imputation to missing data, the analysis gave a relatively robust conclusion to reduce the estimation bias and improve validity. Unmeasured confounders were also treated by E-Value. When compelling randomized trials are not yet forthcoming, it is incrementally valuable that credible evidence for the effect of the HTS in TBI patients was supplied in our study.

This study had several limitations, consistent with those inherent to many large administrative database studies. First, based on electronic records of routine clinical practice, missing data and outliers were common. Second, we did not have data on functional outcomes after discharge, which was arguably an important indicator in this study. Second, as a retrospective study, unmeasured confounding was inevitable. Thus, to quantify the potential implications of it, E-Value sensitivity analysis was used, which demonstrated that the results obtained would be different only if we had omitted the major covariates, which was often not the case in our study. Third, instead of outcome adjudication, our outcomes were defined by ICD-9 and ICD-10 diagnosis codes. Incorrect codes or misclassification bias inevitably exist, so the codes we used were all verified by previous articles[40, 41].

\section{Conclusions}

In this cohort study which enabled a less bias estimation by causal inference methods, we found that HTS was not associated with reduced mortality but with better neurological outcome, accompanied by increased infection, and LOS in msTBI patients. Despite careful methodology involving MSM and trajectory modeling were employed, well-designed, prospective, multicenter simulation studies or RCTs are needed to further clarify the impact of HTS on clinical outcomes.

\section{Abbreviations}

TBI

traumatic brain injury; ICP:intracranial pressure; HTS:hypertonic saline; CBF:cerebral blood flow; CBV:cerebral blood volume; AKI:acute kidney injury; msTBI:moderate-severe traumatic brain injury; GCS:Glasgow Coma Score; RCT:randomized controlled trial; ICU:intensive care unit; MIMIC-IV:medical Information Mart for Intensive Care; elCU-CRD:elCU Collaborative Research Database; IRB:institutional review board; MIT:massachusetts Institute of Technology; BIDMC:beth Israel Deaconess Medical Center; RECORD:reporting of studies Conducted using Observational Routinely collected health Data; BMl:body mass index; ICD:International Classification of Diseases; CCl:charlson comorbidity index; LOS:length of stay; UTI:Urinary tract infection; DVT:deep venous thrombosis; MV:mechanical ventilation; MSCM:Marginal structure Cox model; IPTW:inverse probability of treatment weighting; ESM:electronic supplemental material; GBTM:group-based trajectory modeling; ISS:injury severity score; IQR:interquartile range; SOFA:sepsis related organ failure assessment; AQP4:aquaporin-4; BBB:brain blood barrier; IL-1ß:interleukin; TNF-a:tumor necrosis factor

\section{Declarations}


Funding: This study received the following funding: The San Hang Program of the Second Military Medical University; Three-Year Action Plan for Strengthening Public Health System in Shanghai (20202022) Key Discipline Construction Project (NO: GWV-10.1-XK05).

Conflicts of interestᄆThe authors declared no potential conflicts of interest with respect to the research, authorship, and/or publication of this article.

Availability of data and material: All data were derived from these two public databases.

Code availability: The codes in the study are available upon reasonable request from the corresponding Author (ZJ).

\section{Authors' contributions:}

$\mathrm{FY}, \mathrm{CZ}$, and LB collected, analyzed and interpreted the data regarding the tracheostomy in trauma patients. CP designed the study, and was a major contributor in writing the manuscript. JY performed the statistical analysis. LP, WL, and ZJ participated in the revision of the draft. All authors read and approved the final manuscript.

Ethics approval: Not applicable.

Consent to participate: applicable.

Consent for publication: applicable.

\section{References}

1. Dewan MC, Rattani A, Gupta S, Baticulon RE, Hung YC, Punchak M, Agrawal A, Adeleye AO, Shrime $M G$, Rubiano AM, et al: Estimating the global incidence of traumatic brain injury. $J$ Neurosurg 2018:1-18.

2. Myburgh JA, Cooper DJ, Finfer SR, Venkatesh B, Jones D, Higgins A, Bishop N, Higlett T. Epidemiology and 12-month outcomes from traumatic brain injury in australia and new zealand. The Journal of trauma. 2008;64(4):854-62.

3. Global, regional, and national burden of neurological disorders, 1990-2016: a systematic analysis for the Global Burden of Disease Study 2016. The Lancet Neurology 2019, 18(5):459-480.

4. Steyerberg EW, Wiegers E, Sewalt C, Buki A, Citerio G, De Keyser V, Ercole A, Kunzmann K, Lanyon L, Lecky $F$, et al. Case-mix, care pathways, and outcomes in patients with traumatic brain injury in CENTER-TBI: a European prospective, multicentre, longitudinal, cohort study. Lancet Neurol. 2019;18(10):923-34.

5. Diaz-Arrastia R, Kochanek PM, Bergold P, Kenney K, Marx CE, Grimes CJ, Loh LT, Adam LT, Oskvig D, Curley KC, et al. Pharmacotherapy of traumatic brain injury: state of the science and the road 
forward: report of the Department of Defense Neurotrauma Pharmacology Workgroup. J Neurotrauma. 2014;31(2):135-58.

6. Juul N, Morris GF, Marshall SB, Marshall LF. Intracranial hypertension and cerebral perfusion pressure: influence on neurological deterioration and outcome in severe head injury. The Executive Committee of the International Selfotel Trial. J Neurosurg. 2000;92(1):1-6.

7. Ziai WC, Toung TJ, Bhardwaj A. Hypertonic saline: first-line therapy for cerebral edema? J Neurol Sci. 2007;261(1-2):157-66.

8. Kolmodin L, Sekhon MS, Henderson WR, Turgeon AF, Griesdale DE. Hypernatremia in patients with severe traumatic brain injury: a systematic review. Ann Intensiv Care. 2013;3(1):35.

9. Vedantam A, Robertson CS, Gopinath SP. Morbidity and mortality associated with hypernatremia in patients with severe traumatic brain injury. NeuroSurg Focus. 2017;43(5):E2.

10. Carney N, Totten AM, O'Reilly C, Ullman JS, Hawryluk GW, Bell MJ, Bratton SL, Chesnut R, Harris OA, Kissoon N, et al: Guidelines for the Management of Severe Traumatic Brain Injury, Fourth Edition. Neurosurgery 2017, 80(1):6-15.

11. Oddo M, Poole D, Helbok R, Meyfroidt G, Stocchetti N, Bouzat P, Cecconi M, Geeraerts T, MartinLoeches I, Quintard H, et al. Fluid therapy in neurointensive care patients: ESICM consensus and clinical practice recommendations. Intensive care medicine. 2018;44(4):449-63.

12. Cook AM, Morgan Jones G, Hawryluk GWJ, Mailloux P, McLaughlin D, Papangelou A, Samuel S, Tokumaru S, Venkatasubramanian C, Zacko C, et al. Guidelines for the Acute Treatment of Cerebral Edema in Neurocritical Care Patients. Neurocritical care. 2020;32(3):647-66.

13. Kahle KT, Walcott BP, Simard JM. Continuous hyperosmolar therapy for traumatic brain injuryassociated cerebral edema: as good as it gets, or an iatrogenic secondary insult? Journal of clinical neuroscience: official journal of the Neurosurgical Society of Australasia. 2013;20(1):30-1.

14. Griesdale DE, Sekhon MS, Henderson WR. Hypernatremia and intracranial pressure: more questions than answers. Crit Care (London England). 2013;17(1):401.

15. Tan SK, Kolmodin L, Sekhon MS, Qiao L, Zou J, Henderson WR, Griesdale DE. The effect of continuous hypertonic saline infusion and hypernatremia on mortality in patients with severe traumatic brain injury: a retrospective cohort study. Canadian journal of anaesthesia $=$ Journal canadien d'anesthesie. 2016;63(6):664-73.

16. Goldberger AL, Amaral LA, Glass L, Hausdorff JM, Ivanov PC, Mark RG, Mietus JE, Moody GB, Peng CK, Stanley HE. PhysioBank, PhysioToolkit, and PhysioNet: components of a new research resource for complex physiologic signals. Circulation. 2000;101(23):E215-20.

17. Pollard TJ, Johnson AEW, Raffa JD, Celi LA, Mark RG, Badawi O. The elCU Collaborative Research Database, a freely available multi-center database for critical care research. Scientific data. 2018;5:180178.

18. Benchimol El, Smeeth L, Guttmann A, Harron K, Moher D, Petersen I, Sørensen HT, von Elm E, Langan SM. The REporting of studies Conducted using Observational Routinely-collected health Data (RECORD) statement. PLoS Med. 2015;12(10):e1001885. 
19. Cole SR, Hernán MA, Margolick JB, Cohen MH, Robins JM. Marginal structural models for estimating the effect of highly active antiretroviral therapy initiation on CD4 cell count. Am J Epidemiol. 2005;162(5):471-8.

20. Nagin DS, Odgers CL. Group-based trajectory modeling in clinical research. Ann Rev Clin Psychol. 2010;6:109-38.

21. Pedersen AB, Mikkelsen EM, Cronin-Fenton D, Kristensen NR, Pham TM, Pedersen L, Petersen I. Missing data and multiple imputation in clinical epidemiological research. Clin Epidemiol. 2017;9:157-66.

22. VanderWeele TJ, Ding P. Sensitivity Analysis in Observational Research: Introducing the E-Value. Ann Intern Med. 2017;167(4):268-74.

23. Haneuse S, VanderWeele TJ, Arterburn D. Using the E-Value to Assess the Potential Effect of Unmeasured Confounding in Observational Studies. Jama. 2019;321(6):602-3.

24. Xi G, Keep RF, Hoff JT. Pathophysiology of brain edema formation. Neurosurg Clin North Am. 2002;13(3):371-83.

25. Vik A, Nag T, Fredriksli OA, Skandsen T, Moen KG, Schirmer-Mikalsen K, Manley GT. Relationship of "dose" of intracranial hypertension to outcome in severe traumatic brain injury. J Neurosurg. 2008;109(4):678-84.

26. Alnemari AM, Krafcik BM, Mansour TR, Gaudin D. A Comparison of Pharmacologic Therapeutic Agents Used for the Reduction of Intracranial Pressure After Traumatic Brain Injury. World Neurosurg. 2017;106:509-28.

27. Riha HM, Erdman MJ, Vandigo JE, Kimmons LA, Goyal N, Davidson KE, Pandhi A, Jones GM. Impact of Moderate Hyperchloremia on Clinical Outcomes in Intracerebral Hemorrhage Patients Treated With Continuous Infusion Hypertonic Saline: A Pilot Study. Critical care medicine. 2017;45(9):e947-53.

28. Harrois A, Anstey JR, van der Jagt M, Taccone FS, Udy AA, Citerio G, Duranteau J, Ichai C, Badenes R, Prowle JR, et al. Variability in Serum Sodium Concentration and Prognostic Significance in Severe Traumatic Brain Injury: A Multicenter Observational Study. Neurocritical care. 2021;34(3):899-907.

29. Maas Al, Steyerberg EW, Marmarou A, McHugh GS, Lingsma HF, Butcher I, Lu J, Weir J, Roozenbeek $B$, Murray GD. IMPACT recommendations for improving the design and analysis of clinical trials in moderate to severe traumatic brain injury. Neurotherapeutics: the journal of the American Society for Experimental NeuroTherapeutics. 2010;7(1):127-34.

30. Zhang H, Liu J, Liu Y, Su C, Fan G, Lu W, Feng L: Hypertonic saline improves brain edema resulting from traumatic brain injury by suppressing the NF-KB/IL-1 $\beta$ signaling pathway and AQP4. Experimental and therapeutic medicine 2020, 20(5):71.

31. Roquilly A, Moyer JD, Huet O, Lasocki S, Cohen B, Dahyot-Fizelier C, Chalard K, Seguin P, Jeantrelle C, Vermeersch V, et al. Effect of Continuous Infusion of Hypertonic Saline vs Standard Care on 6-Month Neurological Outcomes in Patients With Traumatic Brain Injury: The COBI Randomized Clinical Trial. Jama. 2021;325(20):2056-66. 
32. Asehnoune K, Lasocki S, Seguin P, Geeraerts T, Perrigault PF, Dahyot-Fizelier C, Paugam Burtz C, Cook F, Demeure Dit Latte D, Cinotti R, et al. Association between continuous hyperosmolar therapy and survival in patients with traumatic brain injury - a multicentre prospective cohort study and systematic review. Crit Care (London England). 2017;21(1):328.

33. Chabok SY, Yazdanshenas H, Naeeni AF, Ziabakhsh A, Bidar SS, Reihanian A, Bazargan-Hejazi S. The impact of body mass index on treatment outcomes among traumatic brain injury patients in intensive care units. European journal of trauma emergency surgery: official publication of the European Trauma Society. 2014;40(1):51-5.

34. Brown CV, Rhee P, Neville AL, Sangthong B, Salim A, Demetriades D. Obesity and traumatic brain injury. The Journal of trauma. 2006;61(3):572-6.

35. Coritsidis G, Diamond N, Rahman A, Solodnik P, Lawrence K, Rhazouani S, Phalakornkul S. Hypertonic saline infusion in traumatic brain injury increases the incidence of pulmonary infection. Journal of clinical neuroscience: official journal of the Neurosurgical Society of Australasia. 2015;22(8):1332-7.

36. Skrifvars MB, Bailey M, Moore E, Mårtensson J, French C, Presneill J, Nichol A, Little L, Duranteau J, Huet O, et al. A Post Hoc Analysis of Osmotherapy Use in the Erythropoietin in Traumatic Brain Injury Study-Associations With Acute Kidney Injury and Mortality. Critical care medicine. 2021;49(4):e394403.

37. Simma B, Burger R, Falk M, Sacher P, Fanconi S. A prospective, randomized, and controlled study of fluid management in children with severe head injury: lactated Ringer's solution versus hypertonic saline. Critical care medicine. 1998;26(7):1265-70.

38. Froelich M, Ni Q, Wess C, Ougorets I, Härtl R. Continuous hypertonic saline therapy and the occurrence of complications in neurocritically ill patients. Critical care medicine. 2009;37(4):143341.

39. Bulger EM, Cuschieri J, Warner K, Maier RV. Hypertonic resuscitation modulates the inflammatory response in patients with traumatic hemorrhagic shock. Ann Surg. 2007;245(4):635-41.

40. Gabella BA, Hathaway JE, Hume B, Johnson J, Costich JF, Slavova S, Liu AY. Multisite medical record review of emergency department visits for traumatic brain injury. Injury prevention: journal of the International Society for Child Adolescent Injury Prevention. 2021;27(S1):i42-8.

41. Warwick J, Slavova S, Bush J, Costich J. Validation of ICD-10-CM surveillance codes for traumatic brain injury inpatient hospitalizations. Brain Inj. 2020;34(13-14):1763-70.

\section{Figures}




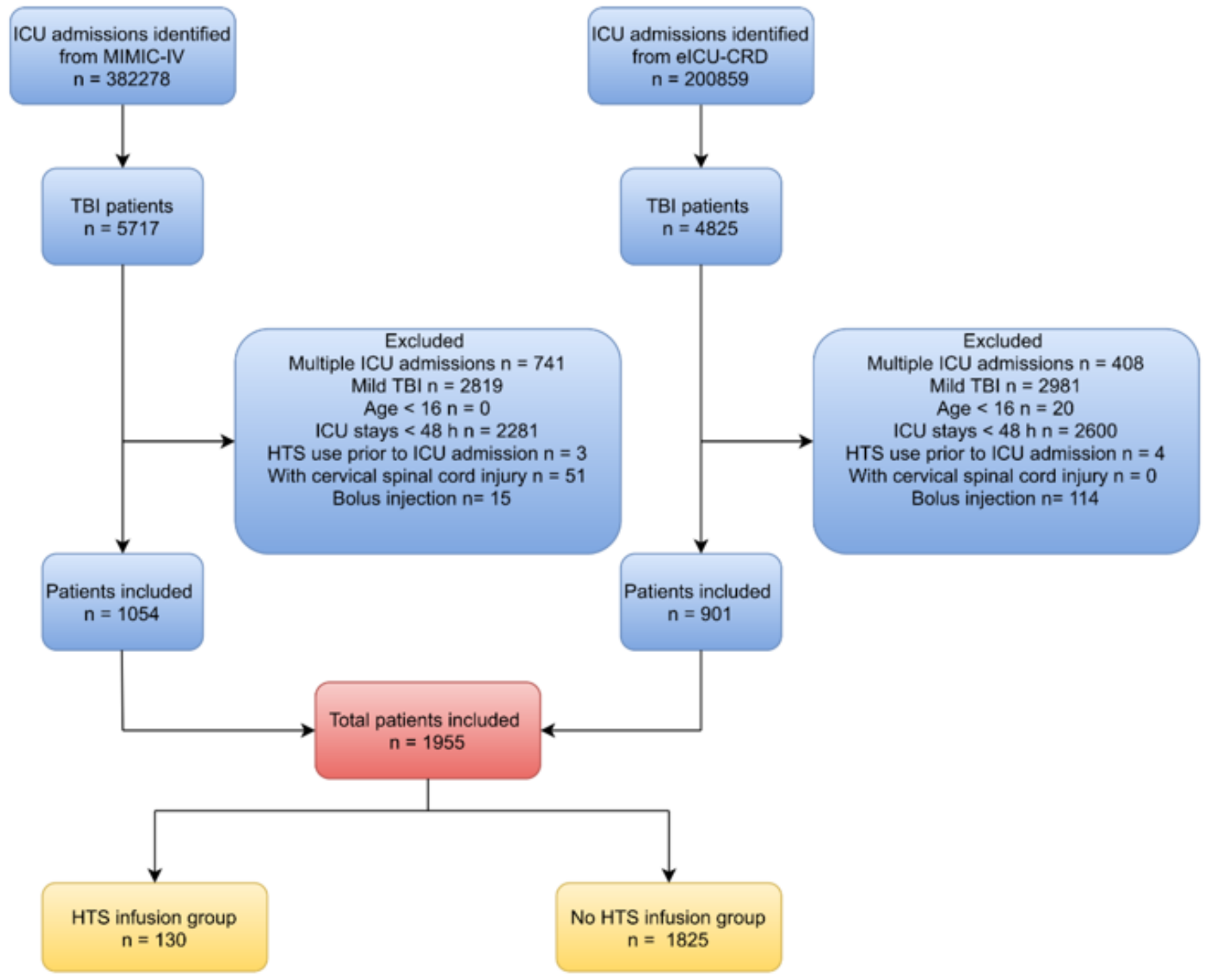

\section{Figure 1}

Flowchart of eligible participants. ICU intensive care unit, TBI traumatic brain injury, HTS hypertonic saline 
Stabilized weights

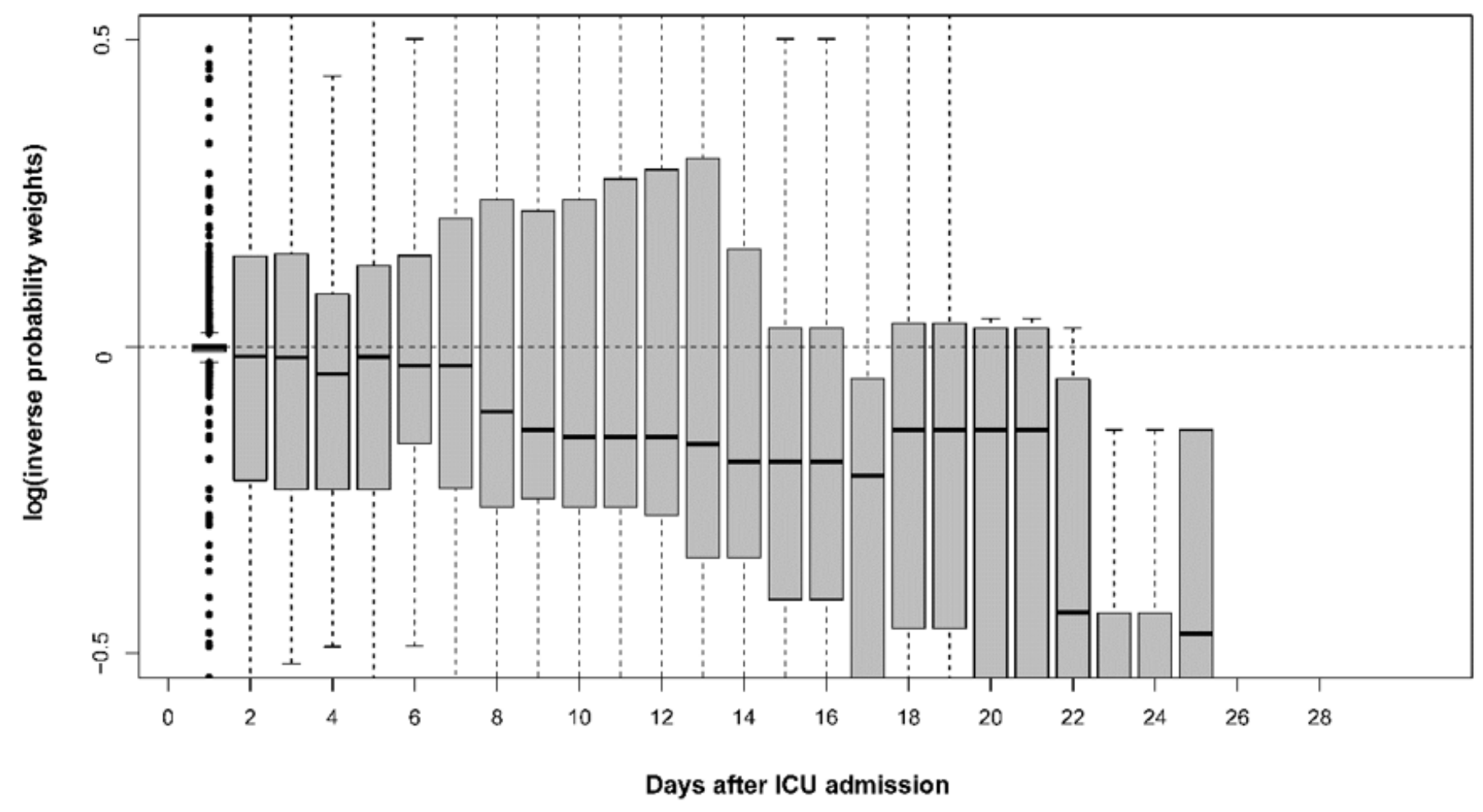

Figure 2

Weights distribution plot for the inverse probability weights that were used to adjust for confounding. ICU intensive care unit 


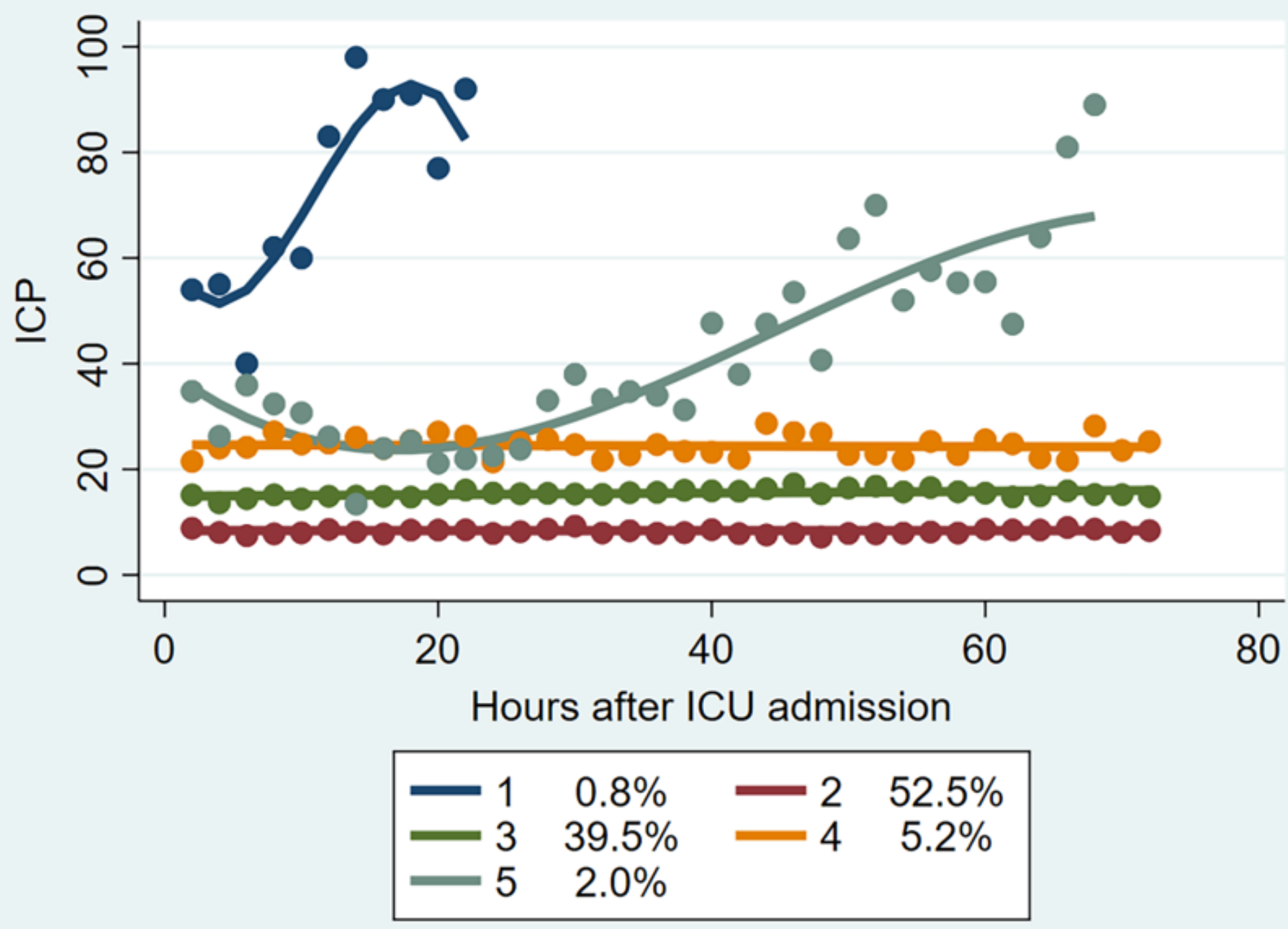

Figure 3

ICP evolution pattern among the five subgroups defined thanks to the trajectory modeling. ICP intracranial pressure, ICU intensive care unit

\section{Supplementary Files}

This is a list of supplementary files associated with this preprint. Click to download.

- Supplementarymaterial.docx 